\title{
Automating the assessment of visual dysfunction after traumatic brain injury
}

\author{
Eric L. Singman
}

Correspondence: esingma1@jhmi.edu

Division Chief, General Eye Services, Wilmer Eye Institute, Wilmer B-29, Baltimore, USA.

\begin{abstract}
Visual dysfunction after traumatic brain injury is prevalent. The determination of the presence of mild traumatic brain injury (mTBI) and the assessment of the degree of injury in the field can be difficult and time consuming, usually requiring specialized personnel and equipment for accuracy. A comprehensive review of visual system dysfunction following mTBI and the availability of automated assessment therein is included in this discussion.
\end{abstract}

Keywords: Automation, TBI, vision, assessment, concussion, telemedicine

\section{Introduction}

The visual pathways span the length and breadth of the brain, making visual functions particularly susceptible to traumatic brain injury (TBI). Although many vision symptoms are reported following a mild traumatic brain injury (mTBI) $[1,2]$ the majority of standard radiologic tests yield normal findings. As a result, there is a growing need to summarize those visual dysfunctions that have been validated through evidence-based medicine. Health care providers who evaluate patients suspected of suffering mTBI need rapid, simple and reliable tests in order to ascertain readiness of the putative mTBIpatient. Many tests are available to assess visual dysfunction. However, they often require administration by specialists trained in the use of a wide array of complex equipment. These specialists would not be expected to be available at the location where the injury occurred. In addition, $\mathrm{mTBI}$ is often a transient condition where patients may require only a week to gradually recuperate [3]. In a combat setting, for example, the ability to re-assess a patient for improvement rear of the lines rather than fully evacuate the patient from the theatre of operations would greatly enhance the efficiency of the process of returning a service person to readiness. Another example is the need to accurately assess for the potential presence of mTBlin sports participants to ensure that they are removed and not exposed to further injury.

Although any visual function can be reduced after injury to the eye or the head, the spectrum of visual changes after $\mathrm{mTBl}$ is more circumscribed and these changes may be more difficult to detect and measure. Patients often feel relatively well. They also may have difficulty describing a visual change. In addition, they may not show obvious clinical signs of injury, even on the standard ophthalmic examination. In the following review, visual dysfunctions that have been reported after TBI will be described along with a mention of their reliability as biomarkers of $\mathrm{mTBI}$ and the processes involved in detecting the dysfunction. In addition, the author will mention whether the testing for the visual dysfunctions has reached the point where automation has been or could be considered. It should be noted that detailed statistics documenting the frequency with which the following deficits occur after $\mathrm{mTBI}$ are not available for most of the problems described [4].

\section{Afferent system defects}

Ocular vision loss

Afferent visual dysfunction can cause visual loss affecting acuity, color vision, brightness detection and contrast sensitivity. Post-traumatic visual loss can be subtle and might not even be noticed by the patient if the problem were monocular. The etiology of monocular vision loss is usually limited to ocular or orbital trauma. Ocular trauma can be assessed in the field using standard ophthalmoscopic techniques. However, this assessment requires a trained examiner who is experienced diagnosing ophthalmic disorders and comfortable using ophthalmic diagnostic tools, most of which are easily portable but might not be readily available at the scene of injury. Retrobulbar trauma causing reduced vision is more difficult to assess. Clinical signs that retrobulbar trauma might have occurred include the presence of proptosis and ptosis. However, a trained examiner can assess for the reduction of visual acuity, loss of color discrimination, a sense of light desaturation, and loss of contrast sensitivity, all of which frequently occur after a traumatic optic neuropathy [5] and therefore are reliable markers of concussion [1]. Simple, hand-held tools such as a flashlight, a hand-held eye chart with letters, colors or contrast gratings are available to assess loss of vision in the field. Visual acuity can now also be assessed using handheld auto-refractors and photo-screeners [6], although there are no reports suggesting that they have been applied routinely to brain injury patients. Validated tests of color vision are also readily available on 
Eric L. Singman Medical Instrumentation 2013,

internet sites $[7,8]$, and therefore would easily be accessible on a small computer or tablet.

\section{Visual field defects}

Visual field defects occur frequently after TBI. They usually signal severe TBI, although mTBI patients who suffer only traumatic optic neuropathy or trauma to the optic chiasm can present with visual field defects $[5,9]$. Manual testing of visual fields by confrontation should detect severe defects. However, more accurate screening of the visual field, although a straightforward task, usually is performed through officebased perimeter technology. It is important to recognize that significant advances have been made in developing portable, compact versions of traditional bowl perimeters suitable for field use [10]. Furthermore, a fieldableperimetry system using virtual reality glasses is now available commercially [11].

\section{Spatial neglect}

Visuo-spatial attention deficits are known to occur after mild TBI [12] but the frequency is unknown. Visuo-spatial attention requires alerting, orienting and executive control (including visual discrimination and decision making). A comprehensive and validated tool available to evaluate for visual attention deficits is the Attention Network Test (ANT) [13]. Patients suffering $\mathrm{mTBl}$ are known to respond to visual cues more slowly and show reduction in the efficiency of resolving visual conflicts [14]. Furthermore, they have been shown to have difficulties specifically with disengaging visual attention from one object of regard, thereby slowing the ability to fix gaze at a novel object of regard [15]. The ANT is now available as a download to a device such as a tablet [16] and therefore should be considered a fieldable test.

\section{Visual midline shift syndrome (VMSS)}

Visual Midline Shift Syndrome (VMSS) has been reported to occur after TBI [17]. The explanation provided for this problem is that a dysfunction of the visuo-spatial recognition process leads to warping (compression and expansion) of the patient's own sense of their body center. The patient has the perception that the environment is compressed (i.e., seems closer) on one side of the body (transversely or antero-posteriorly) and expanded (i.e., seems further away) on the other side. The result in this shift affects balance and posture which can be measured on pressure-detecting treadmills. A simple manual test to detect VMSS is to ask a patient to report when a vertical rod is directly in front of them. More research is needed to explore the utility of VMSS as a reliable biomarker for mTBI. VMSS and other biomarkers of $\mathrm{mTBI}$ have been reported to be detectable through the recording of visual evoked potentials (VEPs) [18]. Notably, wireless recording systems for evoked potentials have recently been developed [19]. In addition, a mobile VEP system is currently available [20] and although this system currently uses a desktop computer, separate imaging screen, and a wired connection to electrodes on the patient's scalp, the developers have been able to compact the system to the level of a laptop computer (personal communication). It seems reasonable to suggest that a compact, wireless system could be created with the merger of the extant technologies. Clearly, challenges to developing a smaller fieldable VEP device would include the need to adequately filter electromagnetic noise from the recordings because the energy of the recorded signals is small, resulting in voltage signals at the microvolt level.

\section{Efferent system defects}

\section{Abnormalities of accommodation}

MTBI has been associated with abnormalities in the ability of the eyes to focus for near vision (i.e., accommodate) and defocus for distance vision. Pseudo-myopia occurs after TBI when the accommodation pathways become over-active and patients may report seeing better at near than at distance. It is unclear how many patients suffering TBI develop pseudomyopia but the condition is well documented [21]; the cause of this spasmodic accommodation is also unknown $[22,23]$. However, it would appear that this refractive change could be a useful marker for TBI. It had been difficult to measure this condition outside the setting of an eye clinic until the recent advent of easily portable, handheld auto-refractors. These devices are now readily available [24-26].

\section{Nystagmus}

Nystagmus is an oscillatory movement of the globe. In can be elicited in some normal patients in extreme horizontal gaze; if it is noted in other circumstances, it is more likely to be abnormal. Some patients have a latent nystagmus that becomes manifest when one eye is occluded. This is a congenital disorder and unlikely to preclude normal functioning. New onset nystagmus can usually be identified by careful visual inspection and is a clear and sensitive biomarker of significant head injury or exposure to neurotoxins. Video-nystagmography (VNG) is a sensitive method to qualitatively and quantitatively describe nystagmus in TBI patients [27]. One might expect that acute onset nystagmus will be obvious to a first responder if not the patient, suggesting that attempts to incorporate VNG into a fielded device would be unnecessary. However, nystagmus, particularly torsional and/or fine nystagmus can be difficult to detect. Portable, compact nystagmography devices have become available and consists of a headmounted display/ detector linked to a computer for data analysis and output [28].

\section{Pursuits}

The abilities of the two eyes to smoothly pursue a moving target and to focus quickly at the anticipated future location a moving target are critical functions of the oculo-motor pathways. The eyes must be able to move conjugately (in the same direction, eg., left, right, etc.) and disconjugately (in opposite directions, eg., toward or away from the midline) without the patient perceiving double vision and without 
degradation of visual clarity. Deficiency of these types of smooth pursuits are common after mild TBI [29]. Further, testing for pursuit disorders may be one of the most sensitive methods to screen for concussion [30,31]. Pursuits can be measured grossly in the field and if markedly abnormal, patients should be evacuated for further evaluation. Subtle deficits in pursuits are more easily detected with automated eye tracking devices and portable versions of these are now available [32].

\section{Saccades}

Saccades are extremely rapid eye movements that are used when a patient changes attention to a novel visual target. They are critically important for both distance viewing and for reading at near. Patients suffering $\mathrm{mTBI}$ often demonstrate deficits in the saccadic systems. They are less able to inhibit saccades [33], and they generate saccades variably [34]; these data suggest that $\mathrm{mTBI}$ patients may be more easily subject to visual distractions. In addition, patients suffering TBI generate hypometric saccades (i.e., they visually undershoot a novel object of regard) [35]. Abnormal saccades during reading can already be measured using portable automated equipment [31].

\section{Extra-ocular motility}

The ocular motility system is very sensitive to TBI and heterophorias (latent strabismus that becomes manifest when fusion is disrupted) have been shown to be extremely common after concussion [36]. Patients with significant manifest strabismus (i.e., heterotropias) will often report frank diplopia. However, mild derangements of ocular motility might be missed if a patient suppresses the information from one eye or if the vision in one eye were reduced. Further, patients might report blurred rather than doubled vision if the strabismus were mild or torsional rather than vertical or horizontal. Gross ocular motility can easily be measured by a trained first-responder in the field. Subtle derangements have required specialized equipment such as the synoptophore, which, although relatively simple to operate, is neither portable nor generally available outside the eye clinic. Advances in automated evaluation of heterophorias have been successful [37] and portable devices for testing phorias are now available $[38,39]$.

\section{Stereo-acuity}

Stereopsis is the ability of the brain to meld the two disparate images from the eyes into a single image that has an appearance of visual depth. It is believed that normal functioning of the midbrain, specifically the superior colliculus, plays a critical role in stereopsis [40]. TBI is known to impair the ability of the eyes to work together through a number of mechanisms, including damage to the nerves that control the eye muscles and to the processing centers that coordinate eye movements. Reduction in stereopsis is a frequent finding in patients suffering $\mathrm{mTBI}$ [41]. Tests of stereo-acuity are quantifiable, sensitive and can now be measured in the field with handheld, portable automated equipment $[38,39]$.

\section{Convergence amplitude}

Convergence is the bilateral rotation of the eyes inward. This disconjugate motion is required when patients gaze at an object closer than 6 meters away. Deficits in convergence (i.e., convergence insufficiency) are among the most common visual disorders demonstrated by patients with mTBI [42]. Convergence amplitudes are fairly simple to quantify with a set of graded prisms, but this equipment is usually not part of the first responder's gear. Reliability of convergence amplitude measurements is dependent upon the level of interest and fatigue of the patient. Therefore, examining patients who are not alert or very fatigued would tend to cause elevated false positive responses. Computerized orthoptics programs are currently available for testing and even treating convergence insufficiency and can easily be loaded onto a tablet computer [43].

\section{Pupillary reaction}

Pupillometry, the quantitative measure of the degree and speed of pupillary responses can now be performed by a handheld, automated device that is simple to use [44]. However, the utility of measuring pupil responses in patients with $\mathrm{mTBI}$ is unclear at present. Patients with severebrain injury and markedly elevated intracranial pressures have been found to demonstrate slowed pupillary responses and anisocoria [45]. However, it is likely that these patients would also have other, more obvious signs of head injury. More research is needed for patients suffering acute, mild TBI to determine whether pupillometry should be incorporated into a validated screening protocol. It should be noted that pupil responses may be abnormal in patients suffering $\mathrm{mTBI}$ associated with traumatic optic neuropathy. It is likely but not assured that these patients will report unilateral vision loss. A first-responder equipped with a pupillometer could evaluate a patient for the presence of an afferent pupillary defect with precision and sensitivity equal to that of a trained physician and use the information to help triage the patient.

\section{Higher order deficits}

The higher order visual responses described below all depend upon efferent pathways extending from within the visual system to non-visual portions of the brain.

\section{Reading speed}

Reading problems are frequent after TBI. Patients lose their place, skip lines of text and have difficulty moving to the next line of print [46]. In addition, a patient's reading speed can be slowed secondary to impaired information processing after mild TBI [47]. The King-Devick Test, in which subjects read aloud numbers from cards is now automated and downloadable to 
a portable computer [48]. This test has been validated as an accurate screening method for identifying athletes suffering concussion [49].

\section{Reaction time}

Visual (as well as auditory and tactile) reaction time is significantly reduced after TBI [50] and is a sensitive assessment for TBI. Simple, low-technology, validated measures of reaction time are available for use in the field and are currently in use by sporting teams. The testing device is a lined ruler stick with a weight on one end which is released near the patient's hand in order to measure how quickly the patient can catch the stick; the long stick is somewhat unwieldy and might not be standard equipment provided to first-responders. Interestingly, automated, computer-presented tests of visual reaction time were among the earliest biophysical evaluations studied; they were critical in demonstrating the effects of lead poisoning on brain function in children [51]. The necessary software should easily be incorporable into a handheld computer.

\section{Memory impairment}

Patients with mTBI have been shown to do less well in episodic memory tasks [52]. There are many methods for testing visual and auditory memory and some automated systems have already been applied to the study of brain injury patients [53]. Sensitive tests of mild memory impairment could easily be made available to first-responders; indeed, some online memory games could likely be validated to serve in this capacity [54].

\section{Orientation to person/time/place}

Patients suffering $\mathrm{mTBI}$ frequently demonstrate deficiencies in orientation. This can be assessed by examiners employing the Rapid Screen of Concussion (RSC). The RSC can be administered by a trained first-responder and has been shown to be sensitive [55] and effective not only for diagnosis but also for differentiating between mild and more severe TBI [56]. The RSC is administered through a series of verbal and visual questions to the patient. Depending upon the battery of tests included, the patient responds verbally, by finger tapping or pointing. It would seem certain that with current levels of computer speech technology, touch screens, etc., we are at the point where the questions employed by the RSC could be presented automatically and the responses provided by the patient could registered, scored and presented on a smartphone or tablet.

\section{Sensitivity to glare}

Patients suffering $\mathrm{mTBI}$ very frequently complain of glare or increased sensitivity to light [57]. The cause of this subjective complaint is unclear although some research suggests abnormal dark adaptation in these patients [58]. Although sensitivity to glare has not yet been quantified, reduction in acuity under glare conditions is a metric available in many eye clinics. It is not known whether glare-acuity measurements can translate into glare sensitivity. Therefore, research is needed to determine normal comfort limits for glare and to validate quantitatively whether $\mathrm{mTBI}$ patients fall outside these limits. Automated glare acuity measurements and devices that can alter brightness to qualitatively assess a patient's response to glare are already available. However, until there is a quantitative way of assessing glare, it would be difficult to use this as a biomarker for mTBI.

\section{Conclusion}

There is a need for rapid, simple, validated methods to ascertain whether an injured patient sustained TBI. This review highlights many of the tests available. Presently, the administration of these tests usually requires experienced examiners and specialized equipment. However, for almost all of the biomarkers of mTBI reviewed, an automated, portable device capable of tele-medically reporting clinical information is already available. Many of these devices require no more than a handheld unit or computer. Some require a remote sensing or presentation device, such as the tests for nystagmus, visual field, pursuits and saccades, in addition to a computer for data acquisition, analysis and output. While there is no single biomarker with perfect sensitivity and specificity for detecting $\mathrm{mTBI}$, it has been reported that batteries of neuropsychological tests can reliable perform this function [59]. It should be mentioned that helmet-mounted devices are already being evaluated to measure impact, and efforts are underway to determine the threshold energy and direction of forces required to cause mTBI [60]. Regardless of the degree or direction of force sustained, testing a seemingly healthy person with a history of head trauma for evidence of mTBl is still vital to determining whether that person can continue to participate in their required activities after the acute trauma. In addition, the ability to evaluate a confirmed patient is crucial to track the success of therapy. For this reason, neuropsychological testing remains important. In addition, it seems logical that the testing would be facilitated if available through a single multicapable, portable, automated device. Such a device would not only assist in the diagnosis of patients but also in monitoring of ongoing care. Further, an automated system would enable remote evaluation, permitting testing and even therapy to occur regardless of the proximity to advanced brain injury treatment and rehabilitation facilities. It is encouraging to see efforts in this regard, such as the DETECT ${ }^{\mathrm{TM}}$ system, a project of Emory University and the Georgia Institute of Technology [61]. Another system capable of performing many aspects of the ophthalmic examination is the $\mathrm{i}^{2} \mathrm{i}^{\mathrm{TM}}$ being developed by Alexander Walsh of the Doheny Eye Institute [62]. Although this device is not specifically aimed at detecting brain injury, it has the potential for incorporating applications necessaryfor this function.

Notably, normal values garnered from large populations for many of the parameters described above are not yet available. 
However, for people employed in high risk fields, such as athletes, police, firefighters or military service personnel, currently available automated testing should be sufficiently convenient to use so that each service person can be tested in the field multiple times before and during deployment. This means that each person would provide their own individual normative data which would likely be preferred to normative data from even a large population when assessing a particular individual for $\mathrm{mTBI}$. At present, all service members of the United States Department of Defense have been required to undergo baseline pre-deployment neurocognitive assessments using a computer-based system called ANAM (Automated Neuropsychological Assessment Metrics) administered by the Neurocognitive Assessment Branch of the Rehabilitation and Reintegration Division [63].

It seems reasonable to also gather as much useful data on validated visual system biomarkers of mTBI prior to deployment. These data would create an excellent baseline for the Traumatic Brain Injury and Vision Injury Registries, such as those being developed by the United States Defense Centers of Excellence for Traumatic Brain Injury and Psychological Health (DCoE) and the United States Department of Defense/ Veterans' Affairs Vision Center of Excellence (DoD/VA VCE), respectively. With appropriate automation, adding this type of data collection to a pre-deployment physical should not add unwieldy amounts of time.

In conclusion, the author strongly supports initiatives to develop an automated, portable, user-friendly, tele-medical and multi-capable device for the visual evaluation of patients suspected of suffering $\mathrm{mTBl}$ and believes the technology may be currently available to succeed in this endeavor.

\section{Competing interests}

The author declares no competing interests.

\section{Acknowledgement and funding}

The author has not received support, financial or otherwise, from other persons, organizations, or sources toward the preparation of this manuscript.

\section{Publication history}

Editor: Errikos Ventouras, Technological Educational Institution of Athens, Greece.

Received: 14-May-2013 Revised: 12-Jun-2013

Re-Revised: 21-Jun-2013 Accepted: 24-Jun-2013

Published: 28-Jun-2013

\section{References}

1. Dougherty AL, MacGregor AJ, Han PP, Heltemes KJ and Galarneau MR: Visual dysfunction following blast-related traumatic brain injury from the battlefield. Brain Inj 2011, 25:8-13. | Article | PubMed

2. Bodack MI: Pediatric acquired brain injury. Ref. B.Optometry 2010, 81:516-27. | Article

3. McCrory P, Meeuwisse W, Johnston K, Dvorak J, Aubry M, Molloy M and Cantu R: Consensus Statement on Concussion in Sport: the 3rd International Conference on Concussion in Sport held in Zurich, November 2008. Br J Sports Med 2009, 43 Suppl 1:i76-90. | Article | PubMed
4. Cockerham GC, Goodrich GL, Weichel ED, Orcutt JC, Rizzo JF, Bower KS and Schuchard RA: Eye and visual function in traumatic brain injury. $J$ Rehabil Res Dev 2009, 46:811-8. | Article | PubMed

5. Atkins EJ, Newman NJ and Biousse V: Post-traumatic visual loss. Rev Neurol Dis 2008, 5:73-81. | PubMed Abstract | PubMed Full Text

6. Matta NS, Singman EL and Silbert DI: Performance of the plusoptiX S04 photoscreener for the detection of amblyopia risk factors in children aged 3 to 5. J AAPOS 2010, 14:147-9. | Article | PubMed

7. online Color Challenge. X-rite 2013. | Website

8. Waggoner TL: Pseudolsochromatic Plate Ishihara Compatible (PIP) Color Vision Test 24 Plate Edition. 2013. I Website

9. Suchoff IB, Kapoor N, Ciuffreda KJ, Rutner D, Han E and Craig S: The frequency of occurrence, types, and characteristics of visual field defects in acquired brain injury: a retrospective analysis. Optometry 2008, 79:259-65. | Article | PubMed

10. Oculus Easyfield. accessed 5-31-2013. | Website

11. VirtualEye ${ }^{\mathrm{TM}}$ Perimeter by BioFormatix. 2013. I Website

12. Halterman Cl, Langan J, Drew A, Rodriguez E, Osternig LR, Chou LS and van Donkelaar P: Tracking the recovery of visuospatial attention deficits in mild traumatic brain injury. Brain 2006, 129:747-53. | Article PubMed

13. Fan J, McCandliss BD, Sommer T, Raz A and Posner MI: Testing the efficiency and independence of attentional networks. J Cogn Neurosci 2002, 14:340-7. | Article | PubMed

14. Xu GQ, Lan Y, Huang DF, Rao DZ, Pei Z, Chen L and Zeng JS: Visuospatial attention deficit in patients with local brain lesions. Brain Res 2010, 1322:153-9. | Article | PubMed

15. Drew AS, Langan J, Halterman C, Osternig LR, Chou LS and van Donkelaar $P$ : Attentional disengagement dysfunction following $m T B I$ assessed with the gap saccade task. Neurosci Lett 2007, 417:61-5. | Article | PubMed

16. Center for Research on Safe Driving - Attention Network Test. Lakehead University 2013. I Website

17. Padula WV, Nelson CA, Benabib R, Yilmaz T and Krevisky S: Modifying postural adaptation following a CVA through prismatic shift of visuospatial egocenter. Brain Inj 2009, 23:566-76. | Article | PubMed

18. Sarno S, Erasmus LP, Lippert G, Frey M, Lipp B and Schlaegel W: Electrophysiological correlates of visual impairments after traumatic brain injury. Vision Res 2000, 40:3029-38. | Article | PubMed

19. Thie J, Klistorner A and Graham SL: Biomedical signal acquisition with streaming wireless communication for recording evoked potentials. Doc Ophthalmol 2012, 125:149-59. | Article | PubMed

20. NOVA-LX Office Based Neuro Optic Vision Assessment. Diopsys 2013. Website

21. London R, Wick B and Kirschen D: Post-traumatic pseudomyopia. Optometry 2003, 74:111-20. | PubMed

22. Chan RV and Trobe JD: Spasm of accommodation associated with closed head trauma. J Neuroophthalmol 2002, 22:15-7. | Article | PubMed

23. Hellerstein LF, Freed $S$ and Maples WC: Vision profile of patients with mild brain injury. J Am Optom Assoc 1995, 66:634-9. I PubMed

24. Wave front Aberrometer. Nidek 2013. | Website

25. SureSight ${ }^{\mathrm{TM}}$ Autorefractor. WelchAllyn 2013. | Website

26. ARK-30 / Palm-ARK Autorefractor. Marco 2013. | Website

27. Armato $E$, Ferri $E$ and Garcia Purrinos F: [Results of videonystagmographic (VNG) analysis in vestibular post-traumatic pathology]. Acta Otorrinolaringol Esp 2001, 52:567-74. | Article | PubMed

28. Chartr 200 VNG/ENG. Otometrics 2013. | Pdf

29. Suh M, Kolster R, Sarkar R, McCandliss B and Ghajar J: Deficits in predictive smooth pursuit after mild traumatic brain injury. Neurosci Lett 2006, 401:108-13. | Article | PubMed

30. Heitger $\mathrm{MH}$, Jones RD and Anderson TJ: A new approach to predicting postconcussion syndrome after mild traumatic brain injury based upon eye movement function. Conf Proc IEEE Eng Med Biol Soc 2008, 
Eric L. Singman Medical Instrumentation 2013,

2008:3570-3. | Article | PubMed

31. Suh M, Basu S, Kolster R, Sarkar R, McCandliss B and Ghajar J: Increased oculomotor deficits during target blanking as an indicator of mild traumatic brain injury. Neurosci Lett 2006, 410:203-7. | Article | PubMed

32. Visagraph - the reading analysis system. Visagraph 2013. | Website

33. Maruta J, Suh M, Niogi SN, Mukherjee P and Ghajar J: Visual tracking synchronization as a metric for concussion screening. J Head Trauma Rehabil 2010, 25:293-305. | Article | PubMed

34. DeHaan A, Halterman C, Langan J, Drew AS, Osternig LR, Chou LS and van Donkelaar P: Cancelling planned actions following mild traumatic brain injury. Neuropsychologia 2007, 45:406-11. | Article | PubMed

35. Williams IM, Ponsford JL, Gibson KL, Mulhall LE, Curran CA and Abel LA: Cerebral control of saccades and neuropsychological test results after head injury. J Clin Neurosci 1997, 4:186-96. | Article | PubMed

36. Doble JE, Feinberg DL, Rosner MS and Rosner AJ: Identification of binocular vision dysfunction (vertical heterophoria) in traumatic brain injury patients and effects of individualized prismatic spectacle lenses in the treatment of postconcussive symptoms: a retrospective analysis. PM R 2010, 2:244-53. | Article | PubMed

37. Han SJ, Guo Y, Granger-Donetti B, Vicci VR and Alvarez TL: Quantification of heterophoria and phoria adaptation using an automated objective system compared to clinical methods. Ophthalmic Physiol Opt 2010, 30:95-107. | Article | PubMed

38. Optec ${ }^{\mathrm{TM}} 2300$ Armed Forces Vision Tester. Stereo Optical Co. 2013. | Website

39. Titmus V4 vision screener. Amplivox 2013. | Website

40. Nashold BS, Jr. and Seaber JH: Defects of ocular motility after stereotactic midbrain lesions in man. Arch Ophthalmol 1972, 88:245-8. | Article | PubMed

41. Miller LJ, Mittenberg W, Carey VM, McMorrow MA, Kushner TE and Weinstein JM: Astereopsis caused by traumatic brain injury. Arch Clin Neuropsychol 1999, 14:537-43. | Article | PubMed

42. Ciuffreda KJ, Kapoor N, Rutner D, Suchoff IB, Han ME and Craig S: Occurrence of oculomotor dysfunctions in acquired brain injury: a retrospective analysis. Optometry 2007, 78:155-61. | Article | PubMed

43. Computerized Home Vergence Exercises. Computer Orthoptics 2013. I Website

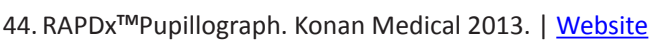

45. Taylor WR, Chen JW, Meltzer H, Gennarelli TA, Kelbch C, Knowlton S, Richardson J, Lutch MJ, Farin A, Hults KN and Marshall LF: Quantitative pupillometry, a new technology: normative data and preliminary observations in patients with acute head injury. Technical note. $J$ Neurosurg 2003, 98:205-13. | Article | PubMed

46. Han Y, Ciuffreda KJ and Kapoor N: Reading-related oculomotor testing and training protocols for acquired brain injury in humans. Brain Res Brain Res Protoc 2004, 14:1-12. | Article | PubMed

47. Johansson B, Berglund $P$ and Ronnback L: Mental fatigue and impaired information processing after mild and moderate traumatic brain injury. Brain Inj 2009, 23:1027-40. | Article | PubMed

48. King-Devick Test Physical Test Kit. King-Devick Test 2013. | Website

49. Galetta KM, Barrett J, Allen M, Madda F, Delicata D, Tennant AT, Branas CC, Maguire MG, Messner LV, Devick S, Galetta SL and Balcer LJ: The King-Devick test as a determinant of head trauma and concussion in boxers and MMA fighters. Neurology 2011, 76:1456-62. | Article | PubMed Abstract | PubMed Full Text

50. Sarno S, Erasmus LP, Lipp B and Schlaegel W: Multisensory integration after traumatic brain injury: a reaction time study between pairings of vision, touch and audition. Brain Inj 2003, 17:413-26. | Article | PubMed

51. Hunter J, Urbanowicz MA, Yule W and Lansdown R: Automated testing of reaction time and its association with lead in children. Int Arch Occup Environ Health 1985, 57:27-34. | Article | PubMed

52. Tsirka V, Simos P, Vakis A, Vourkas M, Arzoglou V, Syrmos N, Stavropoulos $S$ and Micheloyannis $S$ : Material-specific difficulties in episodic memory tasks in mild traumatic brain injury. Int J Neurosci 2010, 120:184-91. | Article | PubMed
53. Mayers LB, Redick TS, Chiffriller SH, Simone AN and Terraforte KR: Working memory capacity among collegiate student athletes: effects of sport-related head contacts, concussions, and working memory demands. J Clin Exp Neuropsychol 2011, 33:532-7. | Article | PubMed

54. Simon Game. Neave 2013. I Website

55. De Monte VE, Geffen GM, May CR and McFarland K: Improved sensitivity of the rapid screen of mild traumatic brain injury. J Clin Exp Neuropsychol 2010, 32:28-37. | Article | PubMed

56. De Monte VE, Geffen GM and Massavelli BM: The effects of posttraumatic amnesia on information processing following mild traumatic brain injury. Brain Inj 2006, 20:1345-54. | Article | PubMed

57. Digre KB and Brennan KC: Shedding light on photophobia. J Neuroophthalmol 2012, 32:68-81. | Article | PubMed Abstract | PubMed Full Text

58. Du T, Ciuffreda KJ and Kapoor N: Elevated dark adaptation thresholds in traumatic brain injury. Brain Inj 2005, 19:1125-38. | Article | PubMed

59. Echemendia RJ, Putukian M, Mackin RS, Julian L and Shoss N: Neuropsychological test performance prior to and following sportsrelated mild traumatic brain injury. Clin J Sport Med 2001, 11:23-31. | Article I PubMed

60. Beckwith JG, Greenwald RM, Chu JJ, Crisco JJ, Rowson S, Duma SM, Broglio SP, McAllister TW, Guskiewicz KM, Mihalik JP, Anderson S, Schnebel B, Brolinson PG and Collins MW: Head impact exposure sustained by football players on days of diagnosed concussion. Med Sci Sports Exerc 2013, 45:737-46. | Article | PubMed

61. Barker JM, Wright DW, Goldstein FC, Ockerman J, Ratcliff JJ and Laplaca MC: The DETECT system: portable, reduced-length neuropsychological testing for mild traumatic brain injury via a novel immersive environment. J Med Eng Technol 2007, 31:161-9. | Article | PubMed

62. Walsh AC. Reinventing the eye exam: four ideas that could change ophthalmology. ARVO Ft. Lauderdale, FL, USA. May 2-6, 2010. I Website

63. Automated Neuropsychological Assessment Metrics Brochure. Army Medicine 2013. | Pdf

\section{Citation:}

Singman E L: Automating the assessment of visual dysfunction after traumatic brain injury. Med Instrum 2013, 1:3. http://dx.doi.org/10.7243/2052-6962-1-3 